\title{
Anatomical and Physiological Effects of Phytohormones on Adventitious Roots Development in Larix kaempferi $\times$ L. olgensis
}

\author{
By H. HAN ${ }^{1)}$, X. M. SuN ${ }^{1), 2)}$, Y. H. XIE ${ }^{2)}$, J. FenG ${ }^{3)}$ and S. G. ZHANG ${ }^{1,2), *)}$
}

(Received $7^{\text {th }}$ June 2012)

\begin{abstract}
Adventitious root development is crucial for cutting propagation in hybrid larch. In the present study, semilignified cuttings of Larix kaempferi $\times$ L. olgensis clones were used to study the morphological and anatomical changes during the different development stages and compare the changes in contents of endogenous phytohormone in two clones with evidently different rooting capacity (25-5 and 23-12), and the effects of exogenous Indole-3-Butyric Acid (IBA) on phytohormone content of a very low native rooting capacity clone (8-9) during the development of adventitious roots. The results showed that the development of adventitious root in semi-lignified cuttings involves three key stages: root cell dedifferentiation and division (14-18 DAC); meristem formation and development (25-35 DAC); root formation and elongation (50-55 DAC). The endogenous phytohormones play a key role during adventitious root development. For 25-5 and 23-12, the level of endogenous phytohormones, especially the ABA content, has an important effect on rooting capacity. For the effects of IBA on 8-9, except lower ABA content, the temporary peak of IAA on the 1 DAC was important for initiating the rooting process. The ratio of $\left(\mathrm{IAA}+\mathrm{GA}_{3}+\mathrm{ZR}\right) / \mathrm{ABA}$ can be used as an indicator of rooting capacity. The anatomical and physiological data described here for semi-lignified cuttings of $L$. kaempferi $\times L$. olgensis clones improves our knowledge of adventitious roots development. Our study will also benefit future research on examining the molecular mechanisms of the adventitious roots development in hybrid larch.
\end{abstract}

Key words: anatomy, IBA, phytohormone ratio, adventitious roots, rooting capacity, Larix kaempferi $\times$ L. olgensis.

\section{Introduction}

The worldwide use of rooted stem cutting is becoming increasingly common in operational plantations to deploy superior genotypes (RITCHIE, 1991). In addition to their fast juvenile growth, larches are much appreciated for afforestation or reforestation for their high quality timber, their wind firmness, their susceptibility to only a

\footnotetext{
1) State Key Laboratory of Tree Genetics and Breeding, Chinese Academy of Forestry, Xiangshan Rd, Beijing, 100091, P. R. China.

2) Research Institute of Forestry, Chinese Academy of Forestry, Xiangshan Rd, Beijing, 100091, P. R. China.

3) Forestry Biotechnology and Analysis Test Center, Liaoning Academy of Forestry Sciences, Chongshan Rd, Liaoning, 110032, P. R. China.

*) Corresponding author: S. G. ZHANG.

Tel. (86)010-62889008, Fax (86)010-62889012.

E-Mail: hhdlx2002@163.com, shougong.zhang@caf.ac.cn.
}

limited number of pests and their amenity (PÂQUES, 2004). Among larches, hybrids of L. kaempferi $\times L$. olgensis, seem likely to play an important role in the mountainous regions of the Northeastern China (SUN et al., 2008; ZHANG et al., 2005). However, before largescale rooted stem cuttings enhanced productivity of the superior genotypes and increased economic benefits, research on how to produce plenty of cuttings with good adventitious roots is needed.

Anatomical and physiological changes are two aspects for studying the adventitious root development. The anatomical changes have been examined in many plants. Soukup et al. (2005) analyzed the anatomical structure and development of adventitious roots in the basal Acorus calamus, to determine what extent those features are related to phylogenetic position. HATZILAZAROU et al. (2006) found the origin of the adventitious roots of gardenia microshoots was located in the cambial ring. NAIJA et al. (2008) studied the anatomical and biochemical changes during adventitious rooting of apple rootstocks MM 106 cultured in vitro. VILLORDON et al. (2009) observed the adventitious root development, and suggested the initial stages of adventitious root development are critical in determining storage root set in sweetpotato. IsMAIL et al. (2011) proved that the produced roots are initiated as the adventitious lateral root with tri-arch xylem strands as compared with the pentaarch of the primary roots of the intact faba bean seedling. MilláN-Orozco et al. (2011) observed the process of adventitious root formation with the eigthweek-old shoots of Cedrela odorata. The above studies showed that clarifying the process of adventitious root development is necessary for further research Adventitious root development is a complex process and regulated by several phytohormones (AlONI et al., 2006; STEPANOVA et al., 2007; WOODWARD and BARTEL, 2005), and most of researches focus on in vitro regeneration, such as loblolly pine (TANG and GUO, 2001), neem (ChATURVEdi et al., 2004), sweet cherry (RǓZIĆ and VUJOVIĆ, 2008), plantain (BUAH et al., 2010), and boscia senegalensis (DAFFALLA et al., 2011). OwAIs (2010) evaluated the Indole-3-Butyric Acid (IBA) treatments on five pomegranate varieties propagation by stem cuttings. Although it has been known that auxin is essential for adventitious root formation, little research is available on the development of adventitious roots in hybrid larch. This study was intended to understand the physiological mechanisms of the development of adventitious roots in $L$. kaempferi $\times L$. olgensis. We studied the morphological and anatomical changes during the different development stages and compared the changes in contents of endogenous phytohormone in two clones with 
evidently different rooting capacity, and the effects of exogenous IBA on phytohormone contents of a very low native rooting capacity clone during the development of adventitious roots.

\section{Materials and Methods}

\section{Cuttings propagation and experimental design}

All plant material used in this study was propagated at Dagujia forest farm in Liaoning province in northeastern China (longitude of $42^{\circ} 2^{\prime} 48^{\prime \prime} \mathrm{N}$, latitude of $124^{\circ} 47^{\prime} 48^{\prime \prime} \mathrm{E}$; altitude of 225-394 m; and annual average temperature of $5.6{ }^{\circ} \mathrm{C}$ ). The clonal cutting orchard of L. kaempferi $\times$ L. olgensis was established in 2003, the donors in this orchard, originating from cuttings, were pruned by hedging, and maintained at $1.4 \mathrm{~m}$ in height (Figure 1a).

In late June 2008, cuttings were collected from the donor (Figure 1b). Each cutting was $15 \mathrm{~cm}$ long, and the cuttings were inserted to a depth of $3 \mathrm{~cm}$ into a medium of pure sand disinfected with potassium permanganate $\left(\mathrm{KMnO}_{4}\right)$. During the early rooting period, cuttings were misted by an automatic spray watering system (Figure $1 c$ ). In late October 2008, cuttings were lifted from the rooting bed and scored for the number of rooted cuttings, number of roots per cutting, and measured for the length of the longest root of the rooted cutting.
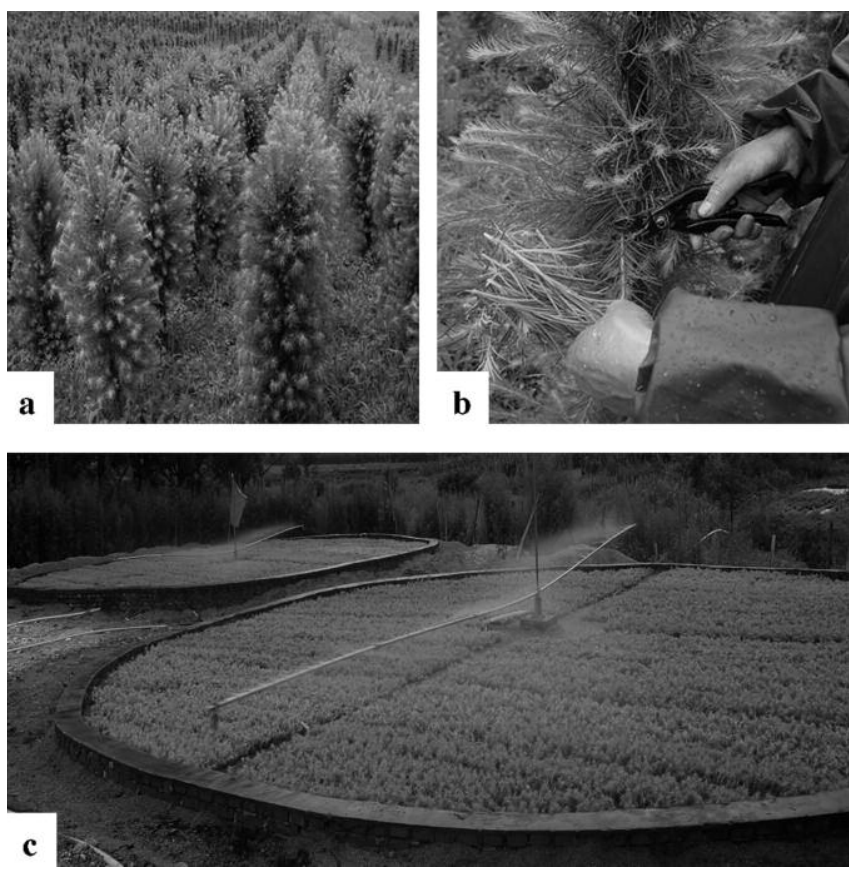

Figure 1. - Schematic of the cuttage process of L. kaempferi $\times$ L. olgensis. (a) Cutting orchard built in 2003. (b) Cuttings are cut from the donors in late June 2008. (c) Automatic spraying every second minute.

A completely randomized block design with 4 replications was used (100 cuttings per replication). We confirm that no specific permits are required for the described field studies, the location is not privatelyowned or protected in any way, and the field studies did not involve endangered or protected species.
Experiment one: Observation the stages of adventitious root development

Four to five cuttings were randomly taken from each replication respectively on day $7,14,18,25,30,35,40$, 45,50 , and 55 (days after cutting [DAC]; the day did cutting was denoted as 0 DAC) as samples for morphological observation. And a $2 \mathrm{~mm}$ thick section was taken from the bottom of each cutting and immediately put into FAA fixative $(5 \%[\mathrm{v} / \mathrm{v}]$ formaldehyde, $5 \%[\mathrm{v} / \mathrm{v}]$ acetic acid, and $50 \%[\mathrm{v} / \mathrm{v}]$ ethanol) to prepare paraffin sections.

\section{Experiment two: Estimation of the effects of phytohormone contents on rooting capacity}

The clones of 25-5 (high native rooting capacity) and 23-12 (low native rooting capacity) were selected from the same cutting orchard, and planted as described in cutting propagation and experimental design. Four to five cuttings from each replication were randomly collected from the two clones on the 0, 14, 25 and 35 DAC respectively, and a $5 \mathrm{~mm}$ thick section was taken from the bottom of each cutting, immediately put into liquid nitrogen, and stored at $-80^{\circ} \mathrm{C}$ until phytohormone extraction.

\section{Experiment three: Estimation of the effects of IBA on rooting capacity}

The clone of 8-9 (very low native rooting capacity) was selected from the cutting orchard. A half of the collected cuttings were treated with an aqueous solution of $0.4 \mathrm{~g} / \mathrm{L}$ IBA and the other half with water (as control, CK) by dipping the bottom of cuttings for $30 \mathrm{~min}$ respectively before being planted in the rooting bed. Four to five cuttings from each replication were randomly collected from the two treatments on the $0,1,14,25$ and 35 DAC respectively, and a $5 \mathrm{~mm}$ thick section was taken from the bottom of each cutting, immediately put into liquid nitrogen, and stored at $-80^{\circ} \mathrm{C}$ until phytohormone extraction.

\section{Methods}

\section{Paraffin sections}

Samples (experiment one) were washed with water repeatedly for five times and dehydrated ethanol with a series of concentrations $(70,85,90$, and $100 \%)$ each for $2 \mathrm{~h}$. Next, the samples were placed in xylene for $2 \mathrm{~h}$ and then infiltrated and embedded with paraffin (treatment with $1 / 2$ paraffin $+1 / 2$ xylene overnight at $38^{\circ} \mathrm{C}$, followed by pure paraffin at $60^{\circ} \mathrm{C}$ for $4 \mathrm{~h}$, repeated three to four times). Finally, the samples were embedded with paraffin in kraft paper folded like a boat and cut into $10-\mu \mathrm{m}$ sections using a rotary microtome. The thin sections were stained with safranin-fast green, enveloped in Canada gum, and imaged using an optical microscope (Olympus BX51).

\section{Phytohormone extraction and measurement}

Samples (experiment two and three) were ground to powder with an iced mortar in $10 \mathrm{ml} 80 \%$ (v/v) methanol extraction buffer containing $1 \mathrm{mmol} / \mathrm{L}$ butylated hydroxytoluene (BHT) as an antioxidant, and incubated at $4{ }^{\circ} \mathrm{C}$ 
overnight, then centrifuged at $5000 \mathrm{rpm}$ for $10 \mathrm{~min}$ at $4^{\circ} \mathrm{C}$. The supernatants were passed through Chromosep C18 columns (C18 Sep-Park Cartridge, Waters Corp., Millford, MA, USA). The phytohormone fractions eluted from the columns were dried in a freeze dryer (Labconco, England), and dissolved in $2 \mathrm{ml}$ phosphate buffer saline (PBS) containing $0.1 \%(\mathrm{v} / \mathrm{v})$ Tween 20 and $0.1 \%$ $(\mathrm{w} / \mathrm{v})$ gelatin $(\mathrm{pH} 7.5)$.

The contents of plant phytohormones, including indole-3-acetic acid (IAA), gibberellin $\left(\mathrm{GA}_{3}\right)$, zeatin riboside (ZR) and abscisic acid (ABA) were determined with an enzyme-linked immunosorbent assay (ELISA) according to that described by WANG et al., (2006). The antibodies against IAA, $\mathrm{GA}_{3}, \mathrm{ZR}$ and $\mathrm{ABA}$ used in ELISA were produced at the Phytophytohormones Research Institute, China Agricultural University, China. Definitely the antibody against IAA is specific exclusively for IAA and not for IBA. Phytohormone content was measured by three replications. The specificity of the monoclonal antibody and the other possible nonspecific immunoreactive interference were checked previously and proved reliable (WANG et al., 2006; YANG et al., 2001a).

\section{Data collection and analysis}

In late October 2008, for each individual cutting, the following traits were investigated: length of the longest root of the rooted cutting, number of roots per cuttnig, and number of rooted cuttings. The rooting rate was calculated by the number of the rooted cuttings and the investigated cuttings. 30 cuttings were investigated per block with 4 replications.
Analyses of variance for each trait were conducted using the General Linear Model (GLM) procedure of the Statistical Analysis System (SAS, version 8.1, Cary, NC). Sources of variation were considered statistically significant when the probability of a greater calculated F-value was less than or equal to 0.05 .

\section{Results}

Morphological and anatomic observations of the development of adventitious roots (Experiment one)

Typical morphological changes during the development of adventitious root were shown in Figure 2. White callus was found in the region between xylem and epidermis at the base of cuttings on the 14 DAC (Figure $2 a$ ); white protrusions which will further develop into adventitious roots were seen (Figure $2 b$ ) on the 30 DAC; the young roots broke through the epidermis and started to elongate continuously on the 35 DAC (Figure 2c); the adventitious roots stopped the elongation and started the lignification process on the 55 DAC (Figure $2 d$ ).

A series of anatomic changes were also noted during the period from the beginning of rooting to the breakthrough of epidermis by adventitious roots (Figure 3). Stimulated by the cut wound, the cortical parenchymal cells began to divide (Figure $3 a$ ). Subsequently, the pith of the stem gradually expanded (Figure $3 b$ ) and the cambial zone opposite the expanded pith became dense cytoplasm and resumed the capacity of division on the $18 \mathrm{DAC}$, the nucleus became large and centered in the cell, which were shown by the densely staining (Figure $3 c$ ), some of cambial cells were began to dedifferentia-
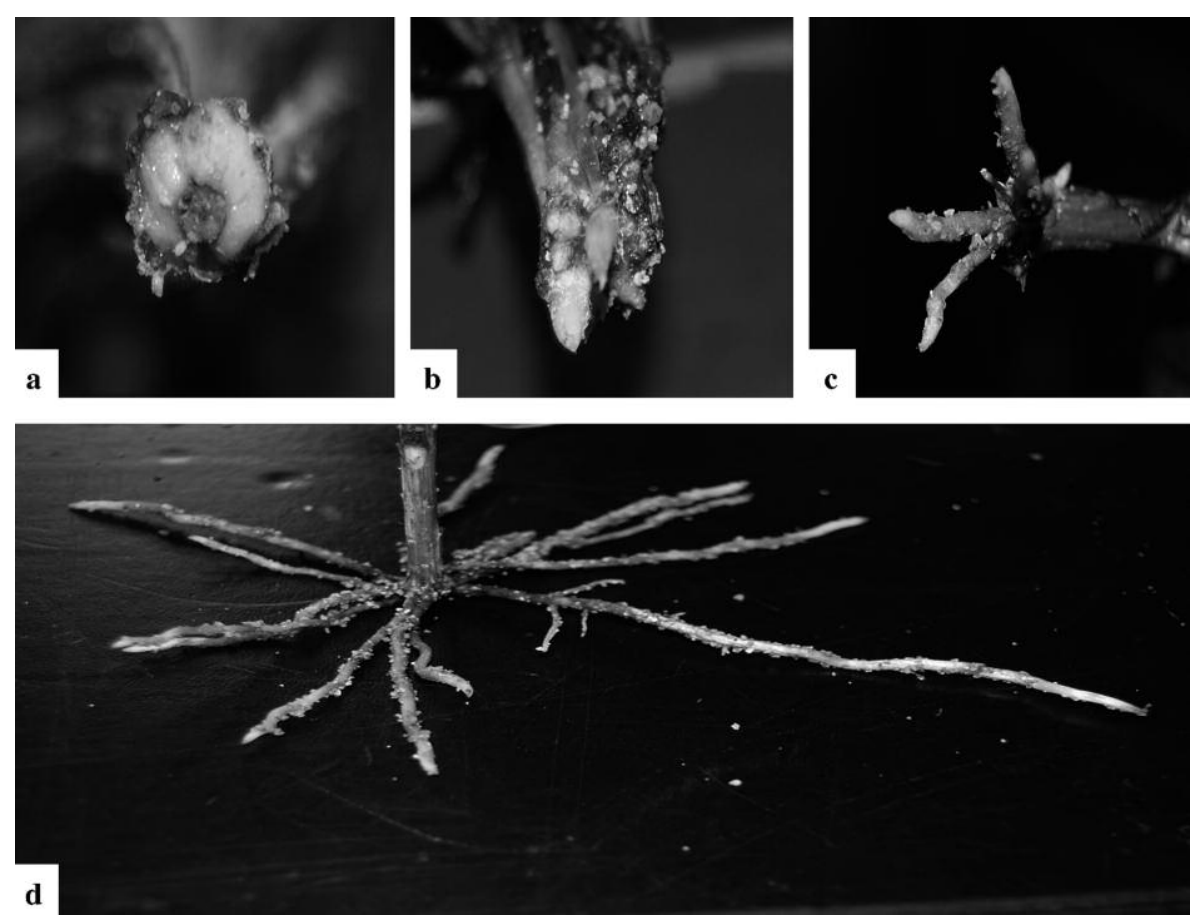

Figure 2. - Morphological development of adventitious roots from L. kaempferi $\times$ L. olgensis cuttings. (a) Callus (14 DAC). (b) White protrusions (30 DAC). (c) Emergence of a young root (35 DAC). (d) Adventitious root extension growth (55 DAC). DAC abbreviate for days after cutting. 
tion and division. After several rounds of cell division, a spherical shape cell mass was formed (Figure $3 d$ ) which were the initial cells of adventitious roots, these initial cells continued to grow to break through the phloem and developed into adventitious roots primordia (Figure $3 e$ ) which further developed into visible adventitious roots (Figure $3 f$ ). The adventitious root continued to elongate and broke through the epidermis.
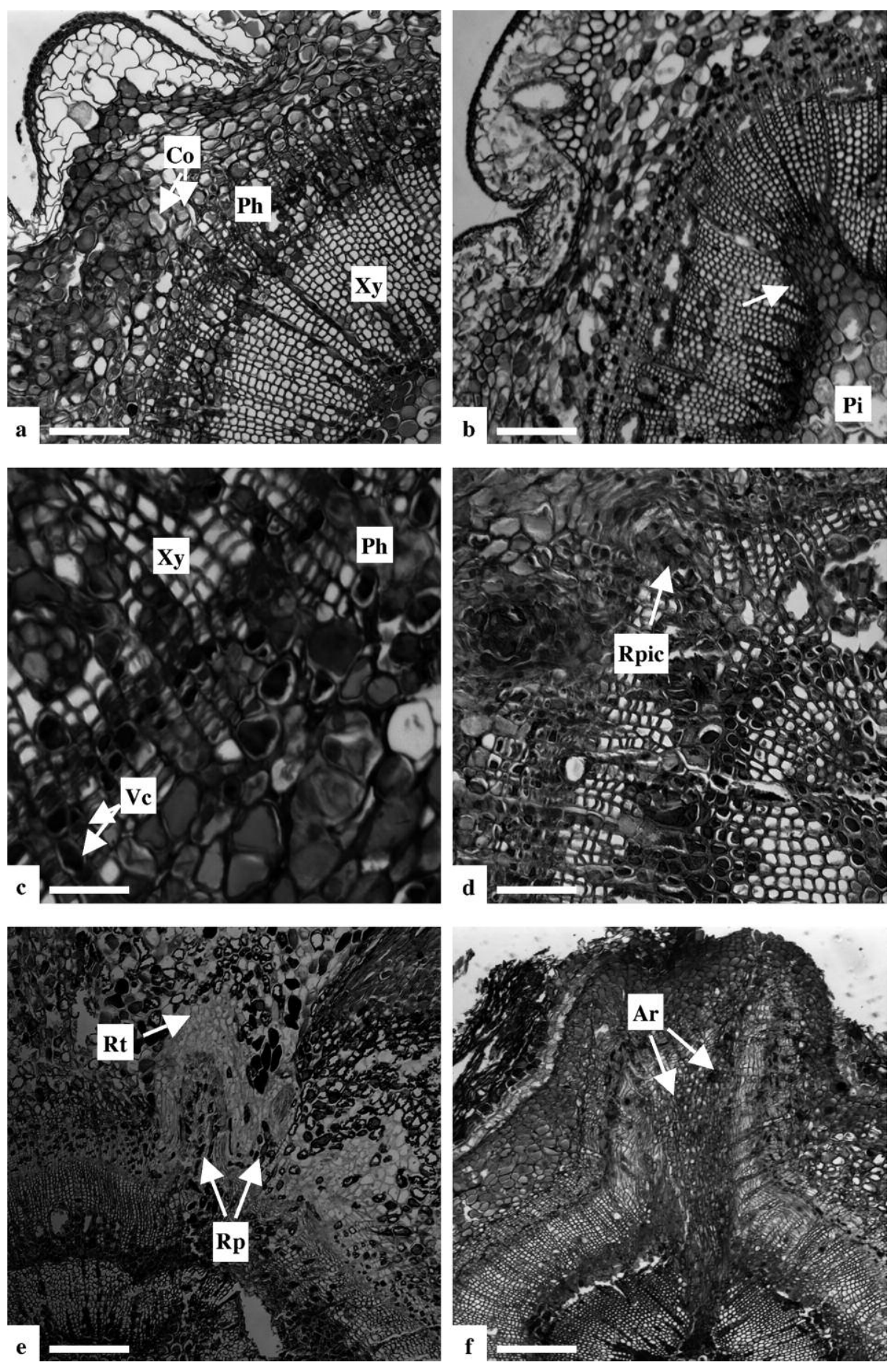

Figure 3. - Transverse sections of the stem of adventitious roots developed from $L$ kaempferi $\times$ L. olgensis cuttings. (a) Anatomical structure of the stem on 7 DAC. (b) 14 DAC, showing pith expander (arrow). (c) 18 DAC, showing early cell activation and a periclinal division (arrow) in the cambial zone. (d) 25DAC, showing root primordium initial cell formation (arrow). (e) $35 \mathrm{DAC}$, showing early root primordia pushing into the cortex (arrow). (f) $50 \mathrm{DAC}$, showing adventitious root emergence and the root vascular system differentiation (arrow). DAC abbreviate for days after cutting.

Abbreviations: $\mathrm{Ar}=$ adventitious root; $\mathrm{Co}=$ cortex; $\mathrm{Ph}=$ phloem $; \mathrm{Pi}=$ pith $\mathrm{Rp}=$ root primordium; Rpic = root primordium initial cell; $\mathrm{Rt}=$ root tip; $\mathrm{Vc}=$ vascular cambium; $\mathrm{Xy}=$ xylem.

Scale bars: $150 \mu \mathrm{m}$ in a; $200 \mu \mathrm{m}$ in b; $55 \mu \mathrm{m}$ in c; $140 \mu \mathrm{m}$ in d; $300 \mu \mathrm{m}$ in e; and $150 \mu \mathrm{m}$ in $\mathrm{f}$. 
Table 1. - Comparison of rooting performance between two clones of L. kaempferi $\times$ L. olgensis.

\begin{tabular}{cccc}
\hline & Rowling rate & Length of longesil ront & \\
Clone & $(\%)$ & $(\mathrm{cm})$ & Root number per cutting \\
\hline $23-12$ & $36.4 \pm 19.4 \mathrm{~B}$ & $3.9 \pm 0.8 \mathrm{~B}$ & $1.9 \pm 0.4 \mathrm{~B}$ \\
$25-5$ & $86.0+6.6 \mathrm{~A}$ & $6.8+1.1 \mathrm{~A}$ & $6.2+1.2 \mathrm{~A}$ \\
\hline
\end{tabular}

Note: Means $\pm \mathrm{SE}$ in a column followed by the same letter do not differ significantly $(P=0.01)$.

Table 2. - Comparison of rooting performance between different treatments of L. kaempferi $\times$ L. olgensis clone.

\begin{tabular}{cccc}
\hline & Rooling rate & Length of longest root & Root number per \\
Treatment & $(\%)$ & $(\mathrm{cm})$ & eutling \\
\hline $\mathrm{CK}$ & $6.8 \pm 1.4 \mathrm{~B}$ & $2.4=0.8 \mathrm{~B}$ & $2.00=0.5 \mathrm{~B}$ \\
$\mathrm{IBA}$ & $73.2 \pm 3.8 \mathrm{~A}$ & $5.3=0.3 \mathrm{~A}$ & $4.8=0.8 \mathrm{~A}$ \\
\hline
\end{tabular}

Note: Means \pm SE in a column followed by the same letter do not differ significantly $(P=0.01)$.

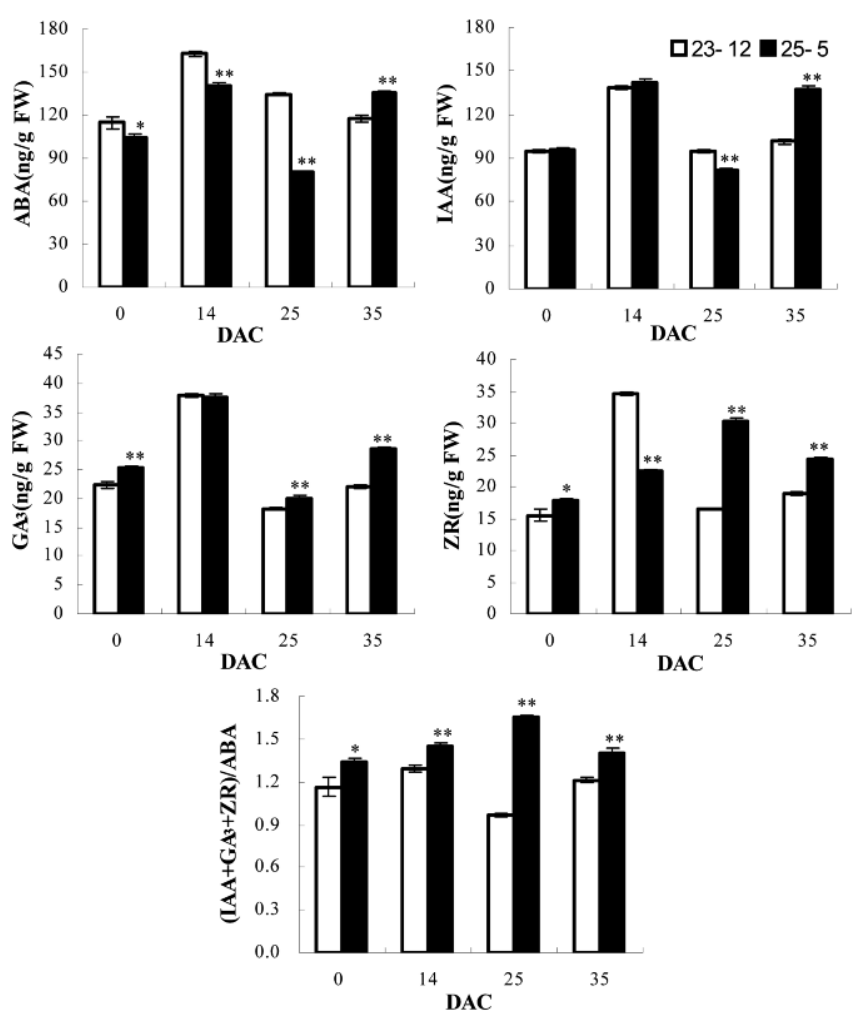

Figure 4. - Changes in the phytohormone contents and ratio during adventitious root development between two clones of L. kaempferi $\times$ L. olgensis. **: $P=0.01$, *: $P=0.05$, Bars represent $\pm \mathrm{SE}, \mathrm{DAC}$ abbreviate for days after cutting.
Effects of endogenous phytohormone contents on rooting capacity (Experiment two)

The clones of 25-5 and 23-12 were obviously different in rooting capacity (Table 1). For the clone 25-5, rooting rate, length of the longest root, and number of roots per cutting were significantly higher than that of the clone $23-12$, with an increase of $1.4,0.7$ and 2.3 times respectively.

Phytohormone contents of the 2 clones were shown in Figure 4. On the $0 \mathrm{DAC}$, the ABA content of the clone 25-5 was lower than that of the clone 23-12 while the IAA content was slightly higher but not statistically significant, and the $\mathrm{GA}_{3}$ and $\mathrm{ZR}$ contents of $25-5$ were significantly higher than that of 23-12. On the 14 DAC, compared to 23-12, the ABA and $\mathrm{ZR}$ contents of $25-5$ were significantly reduced, whereas the contents of IAA and $\mathrm{GA}_{3}$ did not change significantly. On the 25 DAC (meristem of adventitious roots formed), compared to 23-12, the IAA and ABA contents of 25-5 were significantly reduced while the contents of $\mathrm{GA}_{3}$ and $\mathrm{ZR}$ were significantly increased. On the 35 DAC (the primordia of adventitious roots were formed), all the four phytohormones of 25-5 were significantly higher than that of 23-12. The phytohormone ratio $\left(\mathrm{IAA}+\mathrm{GA}_{3}+\mathrm{ZR}\right) / \mathrm{ABA}$ of 25-5, a high native rooting capacity clone, was always significantly higher than that of $23-12$, which is a low native rooting capacity clone, especially on the 14 and the $25 \mathrm{DAC}$, the critical time respectively for cell division and meristem formation of adventitious roots. 

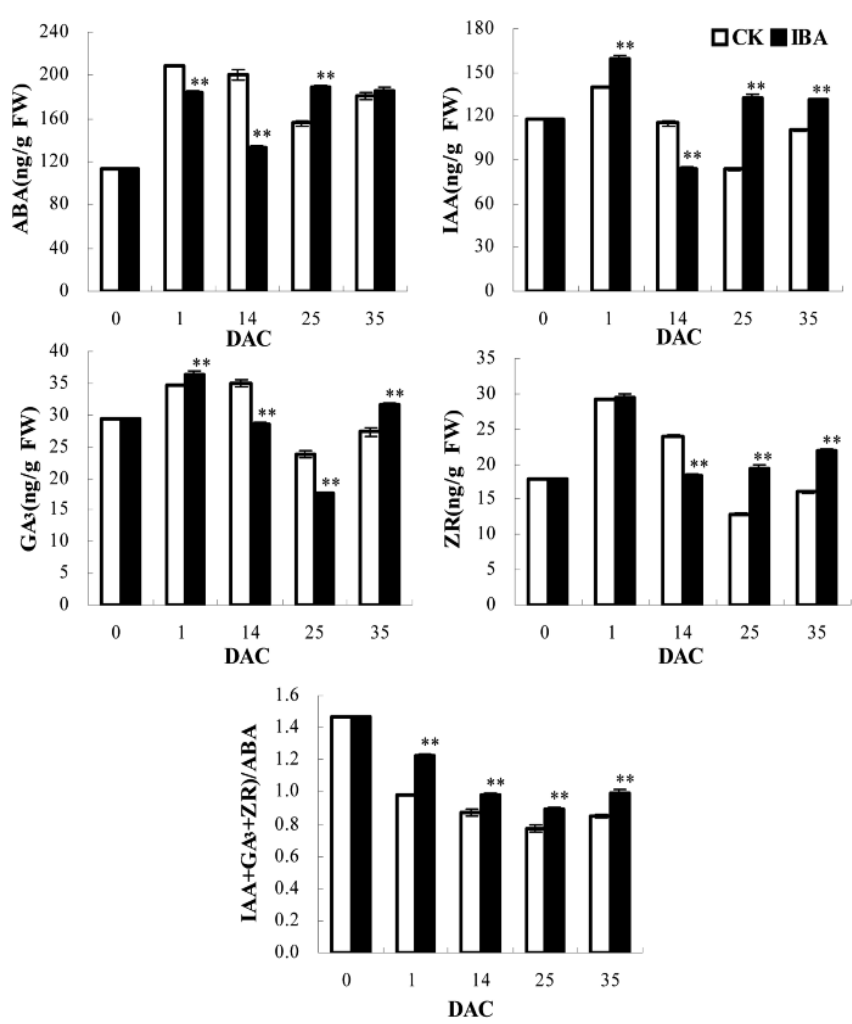

Figure 5. - Changes in the phytohormone contents and ratio during adventitious root development between different treatments of L. kaempferi $\times L$. olgensis clone. **: $P=0.01$, Bars represent $\pm \mathrm{SE}, \mathrm{DAC}$ abbreviate for days after cutting.

\section{Effects of exogenous IBA on phytohormone contents and rooting capacity (Experiment three)}

Rooting capacity of cuttings treated with $0.4 \mathrm{~g} / \mathrm{L}$ IBA were significantly improved (Table 2 ), the rooting rate, the length of the longest root and the number of roots per cutting were increased 9.8, 1.2 and 1.4 times respectively compared with the control.

IBA treatment significantly impacted the content of endogenous phytohormones in the cuttings (Figure 5). On the $1 \mathrm{DAC}$, the ABA content of IBA-treated cuttings decreased significantly, while the IAA content increased significantly. The contents of all the four phytohormones in the IBA-treated cuttings displayed a significant decrease on the $14 \mathrm{DAC}$ (the period of cell division for adventitious roots), and a significant increase (except for $\mathrm{GA}_{3}$ ) on the $25 \mathrm{DAC}$ (the period of meristem formation of adventitious roots) and $35 \mathrm{DAC}$ (the period of primordia formation of adventitious roots) compared with the water-treated cuttings (control). Although the change trend of individual phytohormone content was different between the IBA-treated and the control cuttings during the development of adventitious roots, the phytohormone ratio $\left(\mathrm{IAA}+\mathrm{GA}_{3}+\mathrm{ZR}\right) / \mathrm{ABA}$ of IBA-treated cuttings was always higher than control ones.

\section{Discussion}

Nature of the development of adventitious roots

Adventitious roots development is crucial for cutting propagation in forest species (LUDWIG-MÜLLER et al.,
2005). According to CASSON and LINDSEY (2003), adventitious roots formed from direct organogenesis from established cell types or from callus tissue following mechanical wounding. In this study, white callus formed firstly at the base of the cuttings, and adventitious root primordia formed from the cambial cells opposite the expanded pith several days later, which was similar to Pinus radiata (CAMERon and Thomson, 1969), Pinus taeda (DÍAZ-SAlA et al., 1996), and Quercus (NAALAMLE et al., 2008), indicating that adventitious roots of L. kaempferi $\times$ L. olgensis were formed from callus tissue following wounding by cut.

In this study, it took about 50-55 days for the cuttings of $L$. kaempferi $\times L$. olgensis to develop adventitious roots. According to DíAZ-SALA et al. (1996) and DE KLERK et al. (1999), the development of adventitious roots can be divided into three stages: 14-18 DAC for cell dedifferentiation and division, 25-35 DAC for meristem formation and development, including formation of the initial cells and development of primordia of adventitious roots; 50-55 DAC for adventitious root formation and elongation. It should be noted that the cell division and primordium formation of adventitious roots were almost completed before $35 \mathrm{DAC}$ and the period of 35-55 DAC was mainly for the elongation of adventitious roots. Therefore, the period of 14-35 DAC was an important stage for studying physiological mechanisms during adventitious root development

\section{Relationship between the endogenous phytohormone contents and cuttings rooting capacity}

The development of adventitious roots was closely related to the contents of endogenous phytohormones. $\mathrm{ABA}$ that regulates organ shedding and maturation is considered as an inhibitor for rooting. More recent work with the phytohormone ABA had demonstrated its importance in repressing lateral root development (DEAK and MALAMY, 2005). In this study, the ABA content of the clone 25-5 on the 0 DAC was significantly lower than that of the clone 23-12, and was always lower at the stages of cell dedifferentiation and division, and meristem formation of adventitious roots until the formation of primordium. These results showed that a lower ABA content before the formation of primordium was favorable for rooting capacity.

IAA regulates the development of adventitious roots in many woody species (ALONI et al., 2006; HAN et al., 2009). The IAA content was higher in an easy-to-root clone than in a difficult-to-root clone of $L$. leptolepis (Koo and Hyun, 1996), and a high content of auxin at the beginning of the rooting process was associated with a high rooting rate (CABONI et al., 1997). So, the slightly higher IAA content in the clone 25-5 on the 0 and 14 DAC resulted in a higher rooting capacity. However, when the root meristem began to divide into initial cells of adventitious roots, IAA content was reduced, and it was lower in the clone 25-5 than 23-12, indicating that IAA was probably transported to elsewhere or consumed greatly. IAA content was increased after primordium formation, probably due to the synthesis of IAA by the new developed adventitious roots. 
Gibberellin and Cytokinin are two kinds of phytohormones related to root growth (RUZICKA et al., 2009; TANIмото, 2005), and some researches indicated that the role of Cytokinin in promoting rooting was mainly by promoting differentiation of root meristematic cells (KYOZUKA, 2007) and subsequently regulating the size of the root meristem (DELlo IoIO et al., 2007), this explains why the ZR content in the clone $25-5$ was the highest at the stage of meristem formation of adventitious roots.

The four kinds of phytohormones played different roles in regulating the development of adventitious roots, $\mathrm{ABA}$ was the inhibiting phytohormone, and the other three could promote rooting at different extents. In order to make a comprehensive evaluation of the contents of phytohormones, we proposed to use an index - the ratio of $\left(\mathrm{IAA}+\mathrm{GA}_{3}+\mathrm{ZR}\right) / \mathrm{ABA}$, which was closely related to the rooting capacity, to measure the contents of phytohormones (SuN et al., 2009). In this study, the ratio was higher in 25-5 which is a high native rooting capacity clone, proving that $\left(\mathrm{IAA}+\mathrm{GA}_{3}+\right.$ $\mathrm{ZR}$ )/ABA can be used as an indicator for rooting capacity in practices.

\section{Relationship between exogenous IBA and cuttings rooting capacity}

IAA was the first plant phytohormone used to stimulate rooting of cuttings, and 'synthetic' auxin IBA was also used to promote rooting and was even more effective than IAA (ZIMMERMAN and WILCOXON, 1935). In this study, the rooting capacity of cuttings was significantly improved by IBA treatment, similar to the results in tamarack (FARMER et al., 1992) and in Arabidopsis (LUDWIG-MÜLLER et al., 2005).

When exogenous auxin is applied to induce rooting, the content of auxin usually reaches a peak some hours or days after wounding (GASPAR et al., 1996; GATINEAU et al., 1997). The peak of IAA content in L. kaempferi $\times L$. olgensis appeared on the $1 \mathrm{DAC}$, coinciding with the initiation of the rooting process. This is similar to the findings in Fraxinus angustifolia (ToNON et al., 2001). The temporary increase in endogenous IAA content influenced specific cells that then began to divide actively (DE SMET et al., 2003) and induced the formation of primordium of adventitious roots (HIMANEN et al., 2002; WEIJERS and JÜRGENS, 2004). The effect of exogenous IBA on promoting rooting was mainly due to the ability of regulating endogenous IAA and the influences on other phytohormones at the same time. The ABA content was remarkably reduced, and the contents of $\mathrm{GA}_{3}$ and ZR were increased by different extents on the 1 DAC. At the next stages of root development (14 and 25 DAC), all four phytohormone contents of control cuttings were decreased, they might be consumed by root cells division and root meristem formation (SUN et al., 2009). However, the contents of phytohormones (except $\mathrm{GA}_{3}$ ) were increased by IBA treatment, especially for IAA on the $25 \mathrm{DAC}$, and this was probably resulted from the slow release of IAA from IBA (EPSTEIN and LUDWIGMÜLlER, 1993). These results suggested that either IBA itself was active or it modulated the activity of IAA (VAN DER KRIEKEN et al., 1992; 1993) to induce more roots.
Many researches showed that auxin has interaction with other phytohormones, such as gibberellin (FRIGERIO et al., 2006; Fu and HARBERD, 2003) and cytokinin (Skoog and Miller, 1957). We proposed the ratio of $\left(\mathrm{IAA}+\mathrm{GA}_{3}+\mathrm{ZR}\right) / \mathrm{ABA}$ used as an index for measuring the rooting capacity, and the results indicated that the ratio was higher in IBA-treated cuttings than control ones, and so was the rooting capacity of the cuttings.

\section{Conclusions}

Our results demonstrate that the development of adventitious roots in semi-lignified cuttings of Larix kaempferi $\times L$. olgensis consists of three key stages: 14-18 DAC for cell dedifferentiation and division; 25-35 DAC for meristem formation and development; 50-55 DAC for root formation and elongation. Phytohormones play a role at each development stages. For the clones with evidently different rooting capacity (25-5 and 23-12), the contents of endogenous phytohormones, especially a lower ABA content, has an important effect on rooting capacity. For the effects of IBA treatment on phytohormone contents of a very low native rooting capacity clone (8-9), except lower ABA content, the temporary peak of IAA content was important for the formation and development of adventitious roots. The ratio of $\left(\mathrm{IAA}+\mathrm{GA}_{3}+\mathrm{ZR}\right) / \mathrm{ABA}$ was proposed as an indicator for the rooting capacity of cuttings in practices. The anatomical and physiological data described here for semi-lignified cuttings of $L$. kaempferi $\times$ L. olgensis improves our knowledge of adventitious roots development and provides a basis for practical applications. Our study will also benefit future research on examining the molecular mechanisms of the adventitious roots development in hybrid larch.

\section{Acknowledgments}

We are very grateful to Prof. Dr. YongQI ZHENG for good suggestion and manuscript writing (Research Institute of Forestry, Chinese Academy of Forestry, China). We also thank http://www.textcheck.com/text/ page/index for checking the manuscript, please see: http://www.textcheck.com/certificate/u6FsuB. This work was made possible by financial support from the National Science Foundation (30972393) and State 973 Plan (2009CB119100) of China.

\section{References}

Aloni, R., E. Aloni, M. Langhans and C. I. Ullrich (2006): Role of cytokinin and auxin in shaping root architecture: Regulating vascular differentiation, lateral root initiation, root apical dominance and root gravitropism. Ann Bot (Lond) 97: 883-893.

Baltunis, B. S., M. S. Greenwood and T. Eysteinsson (1998): Hybrid vigor in Larix: growth of intra- and interspecific hybrids of Larix deciduas, L. kaempferi after 5 years. Silvae Genet 47: 288-293.

Buah, J. N., E. Danso, K. J. TaAh, E. A. Abole, E. A. BediAKo, J. AsIEDU and R. BAIDOO (2010): The effects of different concentrations cytokinins on the in vitro multiplication of plantain (Musa sp.). Biotechnology 9(3): 343-347. 
Caboni, E., M. G. Tonelli, P. Lauri, P. IAcovacci, C. Kevers, C. Damiano and T. Gaspar (1997): Biochemical aspects of almond microcuttings related to in vitro rooting ability. Biol Plant 39: 91-97.

Cameron, R. J. and G.V. Thomson (1969): The vegetative propagation of Pinus radiata: root initiation in cuttings. Bot Gaz 130(4): 242-251.

Casson, S. A. and K. Lindsey (2003): Genes and signalling in root development. New Phytologist 158: 11-38.

Chaturvedi, R., M. K. Razdan and S. S. BhoJwani (2004): In vitro morphogenesis in zygotic embryo cultures of neem (Azadirachta indica A. Juss.). Plant Cell Reports 22(11): 801-809.

Daffalla, H. H., E. Abdellatef, E. A. Elhadi and M. M. KHALAFALla (2011): Effect of Growth Regulators on In Vitro Morphogenic Response of Boscia senegalensis (Pers.) Lam. Poir. Using Mature Zygotic Embryos Explants. Biotechnol Res Int. doi:10.4061/2011/710758.

DEAK, K. I. and J. MALAMY (2005): Osmotic regulation of root system architecture. The Plant Journal 43(1): $17-28$.

De Klerk, G. J., W. Van Der Krieken and J. C. De Jong (1999): The formation of adventitious roots: new concepts, new possibilities. In: Vitro Cellular, Development Biology. Plant 35(3): 189-199.

Dello Ioio, R. D., F. S. LinhaRes and E. ScACChi (2007): Cytokinins determine Arabidopsis root-meristem size by controlling cell differentiation. Curr Biol 17: 678-682.

De Smet, I., L. Signora, T. Beeckman, D. Inze, C. H. FoYer and H. M. ZHANG (2003): An abscisic acid-sensitive checkpoint in lateral root development of Arabidopsis. Plant J 33: 543-555.

Díaz-Sala, C., K. W. Hutchison, B. Goldfarb and M. S. GREENWOOD (1996): Maturation-related loss in rooting competence by stem cuttings: the role of auxin transport, metabolism and tissue sensitivity. Physiol Plant 97: 481-490.

EPSTEIN, E. and J. LUDWIG-MÜLLER (1993): Indole-3butyric acid in plants: occurrence, biosynthesis, metabolism, and transport. Physiologia Plantarum 88 382-389.

Farmer, J. R., J. T. Durst, S. T. Deng and J. T. Yang (1992): Effect of clones, primary ramets, and age of stock plants on tamarack rooting. Silvae Genet 41(1): 22-24.

Fu, X. D. and N. P. HARBERD (2003): Auxin promotes Arabidopsis root growth by modulating gibberellin response. Nature 421: 740-743.

Frigerio, M., D. Alabadi and J. Perez-Gomez (2006): Transcriptional regulation of gibberellin metabolism genes by auxin signaling in Arabidopsis. Plant Physiol 142: 553-563.

Gaspar, T., J. F. Hausman, C. Penel, L. Jouve, J. MartinTANGuY, M. ARIBAUd and H. GREPPIN (1996): Peroxidase as an indissociable factor of auxin and polyamine metabolisms in the induction of rooting and flowering, pp 226-234. In: Plant peroxidases: biochemistry and physiology, edited by C. Obinger, U. Burner, R. EBermann, C. Penel and H. Greppin, Proc. IV Int. Symp. Univ Geneva.

Gatineau, F., J. G. Fouche, C. Kevers, J. F. Hausman and T. GASPAR (1997): Quantitative variations of indolyl compounds including IAA, IAA-aspartate and serotonin in walnut microcuttings during root induction. Biol Plant 39: 131-137.
HAN, H., S. G. ZHANG and X. M. Sun (2009): A review on the molecular mechanism of plants rooting modulated by auxin. African Journal of Biotechnology 8(3): 348-353.

Hatzilazarou, S. P., T. D. Syros, T. A. Yupsanis, A. M. Bosabalidis and A. S. Economou (2006): Peroxidases, lignin and anatomy during in vitro and ex vitro rooting of gardenia (Gardenia jasminoides Ellis) microshoots. J Plant Physiol 163(8): 827-836.

Himanen, K., E. Boucheron and S. VAnneste (2002): Auxin-Mediated cell cycle activation during early lateral root initiation. Plant Cell 14: 2339-2351.

Ismail, R. M., H. E. Elazab, G. M. Hussein and E. A. Metry (2011): In vitro root induction of faba bean (Vicia faba L.). GM Crops 2(3): 176-181.

Koo, Y. and J. HYUN (1996): Initial root development of Larix leptolepis Gordon cuttings as related to organic substances and cutting date. J Kor Forestry Soc 85: 300-308.

KyozUKA, J. (2007): Control of shoot and root meristem function by cytokinin. Curr Opin Plant Biol 10: 442-446.

Ludwig-Müller, J., A. VerTocNiK and C. D. TOWN (2005): Analysis of indole-3-butyric acid-induced adventitious root formation on Arabidopsis stem segments. Journal of Experimental Botany 56(418): 2095-2105.

Mellán-Orozco, L., E. Corredoira and C. SAN José Mdel (2011): In vitro rhizogenesis: histoanatomy of Cedrela odorata (Meliaceae) microcuttings. Rev Biol Trop 59(1): 447-453.

NAAlamle, A. J., J. P. Domonick JR. and N. Bassuk (2008): Adventitious root formation in stem cuttings of Quercus bicolor and Quercus macrocarpa and its relationship to stem anatomy. J Amer Soc Hort Sci 133: 479-486.

Naija, S., N. Elloumi, N. JBIR, S. Ammar and C. Kevers (2008): Anatomical and biochemical changes during adventitious rooting of apple rootstocks MM 106 cultured in vitro. C R Biol 331(7): 518-525.

OwAIS, S. J. (2010): Rooting response of five pomegranate varieties to indole butyric acid concentration and cuttings age. Pak J Biol Sci 13(2): 51-58.

PÂQUES, L. E. (2004): Roles of European and Japanese larch in the genetic control of growth, architecture and wood quality traits in interspecific hybrids (Larix $\times$ eurolepis Henry). Ann For Sci 61: 25-33.

RITCHIE, G. A. (1991): The commercial use of conifer rooted cuttings in forestry: A world overview. New For 5: 247-275.

RuŽIĆ, D.V. and T. I. VuJović (2008): The effects of cytokinin types and their concentration on in vitro multiplication of sweet cherry cv. Lapins (Prunus avium L.). Horticultural Science 35(1): 12-21

Ruzicka, K., M. Simásková, J. Duclercq, J. Petrásek, E. Zazímalová, S. Simon, J. Friml, M. C. Van Montagu, and E. BENKOVÁ (2009): Cytokinin regulates root meristem activity via modulation of the polar auxin transport. PNAS 106(11): 4284-4289.

Skoog, F. and C. O. Miller (1957): Chemical regulation of growth and organ formation in plant tissue cultured in vitro. Symp Soc Exp Biol 54: 118-131.

Soukup, A., L. James, J. R. Seago and V. Olga (2005): Developmental anatomy of the root cortex of the basal monocotyledon, Acorus calamus (Acorales, Acoraceae). Annals of Botany 96: 379-385.

Stepanova, A. N., J. Yun, A.V. Likhacheva and J. M. Alonso (2007): Multilevel interactions between ethylene and auxin in Arabidopsis roots. Plant Cell 19: 2169-2185. 